\title{
ESTUDO CINÉTICO DA INTERAÇÃO DE 5-BROMODEOXIURIDINA NAS CÉLULAS MONONUCLEADAS: CD45+ E CD34- PARA TERAPIA CELULAR MODELO EXPERIMENTAL EM MURINOS
}

\author{
KINETIC STUDY OF THE 5-BROMODEOXIURIDINE INTERACTION WITH MONONONUCLEATED \\ CELLS: CD45+ AND CD34- FOR CELL THERAPY AN EXPERIMENTAL MURINE MODEL
}

\author{
Katherine Athayde Teixeira de Carvalho ${ }^{1-3}$, Julio César Francisco ${ }^{3}$, Rossana Baggio Simeoni², Larissa Zocche', Ana Carolina \\ Irioda ${ }^{3}$, Jeane Edwiges Ruvinski², Ricardo Correa Cunha ${ }^{3}$, Leila de Oliveira ${ }^{4}$
}

\begin{abstract}
RESUMO
A 5-bromodeoxiuridina é uma substância marcadora análoga da timidina que permite a realização de técnicas como a imunocitoquímica e utilizada para identificar as células que se proliferam na fase S do ciclo celular. Objetivo: Estabelecer protocolo do tempo de incubação para marcação celular com a 5-bromodeoxiuridina de células-tronco mononucleadas derivadas da medula óssea através de estudo cinético para sua utilização na bioengenharia tecidual. Métodos: 16 ratos machos da linhagem Wistar com peso médio de $300 \mathrm{~g}$ foram utilizados. A coleta do sangue da medula óssea foi realizada através de punção-aspiração da crista ilíaca. O isolamento das células-tronco derivadas da medula óssea (fração mononucleada) foi feito através do gradiente de densidade $(\mathrm{d}=1,077)$. As suspensões de células-tronco mononucleadas da medula óssea (CD45+ e CD34-) foram incubadas com 5-bromodeoxiuridina na concentração final de $10 \mathrm{mM}$ à $37^{\circ} \mathrm{C}$ em períodos préestabelecidos de 1h, 5h, 16h e 24h e para cada amostra obtida, seguidos do método de imunofluorescência direta. Resultados: Em todos os períodos de incubação a marcação positiva para 5-bromodeoxiuridina foi observada, demonstrando-se células em replicação em atividade proliferativa naquelas suspensões; mas a partir das $16 \mathrm{hs}$, as marcações foram em maior número e mais evidentes $(55 \% \pm 4 \%, 16 \mathrm{~h}$ e $53 \pm 6 \%$, $24 \mathrm{~h}$ versus $12 \% \pm 3$, $1 \mathrm{~h}$ e $23 \pm 4$, 5h). Conclusões: Os períodos de incubação BrdU para células-tronco da medula óssea (fração mononucleada) a partir de 16hs demonstraram ser a melhor opção para evidenciar a atividade proliferativa, sugerindo seu uso incluído na rotina de terapia celular na avaliação prognóstica do potencial de integração no tecido transplantado e substituindo a timidina radioativa.
\end{abstract}

Descritores: Células-tronco, Medula Óssea, Terapia Celular,

\footnotetext{
Instituições:

1 Faculdades Pequeno Príncipe e Instituto Pelé Pequeno Príncipe de Pesquisa - Curitiba / PR - Brasil

2 Instituto de Ciências Biológicas e da Saúde, da Pontifícia Universidade Católica do Paraná (ICBS-PUCPR) - Curitiba / PR - Brasil

${ }^{3}$ Divisão de Bioprocessos do Departamento de Engenharia da UFPR - Curitiba / PR Brasil

${ }^{4}$ Hospital de Clínicas da UFPR - Hematologia/Imunofenotipagem - Curitiba / PR - Brasil
}

Endereço para correspondência:

Katherine Athayde Teixeira de Carvalho

Al. Carlos de Carvalho, 655 - 1405 - Curitiba / PR - CEP: 80430-180 - Brasil

Tel./Fax: (41) 32231689

E-mail: katherincarv@gmail.com

Recebido em: 25.08.2006

Aceito em: 20.08 .2008

\section{INTRODUÇÃO}

Nos últimos anos, a medicina regenerativa também chamada de engenharia tecidual vem desenvolvendo e abrindo perspectivas inovadoras para o tratamento de várias doenças, visando à substituição de células mortas ou não funcionais por células-tronco de diversas origens, devido ao seu potencial regenerativo. Essa nova técnica está sendo aplicada em um amplo espectro de doenças humanas, incluindo muitos tipos de cânceres, doenças neurológicas como Parkinson, injúrias na medula espinhal, diabetes e miocardiopatias. ${ }^{1}$

Em relação às células-tronco da medula óssea (CTMO), a grande vantagem de sua utilização é sua facilidade de obtenção por aspiração da medula óssea do próprio paciente, o que possibilita o transplante autólogo, eliminando a busca de doadores e efeitos adversos da terapia imunossupressora.

As CTMO são capazes de proliferar gerando cópias de si mesmas para sua manutenção, ou de se diferenciarem gerando descendentes maduros e especializados.

Células-tronco adultas surgem na fase tardia da embriogênese e do desenvolvimento fetal, sendo pluripotentes. ${ }^{2}$ 
Essas células-tronco adultas, quando isoladas da medula óssea (MO) adulta possuem duas linhagens. A linhagem hematopoiética, contendo células mononucleadas (1-2\% do sangue da medula total) apresentando precursores de células endoteliais e hematopoiéticas e a linhagem mesenquimal $(<0,05 \%$ do sangue da medula total) que possui precursores com pluripotencialidade para células derivadas do mesoderma. ${ }^{3,4}$

As células-tronco mesenquimais e pluripotentes da MO necessitam ser expandidas in vitro para obtenção de maior quantidade e, na dependência do meio, possuem capacidade de diferenciação em linhagens miogênicas, osteogênicas, condrogênicas e adipogênicas. ${ }^{5,6}$ Muito recentemente, foi observado que célulastronco mesenquimais da medula óssea (CTMMO) in vitro podem adquirir características fenotípicas e genotípicas de células precursoras neuronais, quando em meio condicionado. ${ }^{7}$

As CTMO possuem a propriedade de plasticidade, que confere a possibilidade de expressar características de outras linhagens celulares e com potencial de auto-regeneração, havendo possibilidade de mobilização destas células-tronco da medula óssea para a circulação através de ações de fármacos, como o fator estimulante de granulócitos. ${ }^{8}$

Considerando-se que populações diferenciadas de células nos vertebrados não são permanentes e que as células estão continuamente sendo substituídas por células funcionais, elas são produzidas durante a vida adulta para manutenção da homeostase; a terapia celular foi introduzida para otimizar este processo, que na maioria das vezes é insuficiente para o reparo do tecido e para restituir sua funcionalidade. Na homeostase, por simples duplicação de células diferenciadas, essas células se dividem para dar outras células-filhas do mesmo tipo: por divisão celular ou por geração a partir de células-tronco relativamente indiferenciadas, através de um processo que envolve ativação e inativação de genes para as mudanças fenotípicas celulares.

O ciclo celular ocorre em duas etapas. A primeira é a fase G1, que corresponde ao período de crescimento celular e executa suas funções; a segunda é a fase $\mathrm{S}$, que determina o início de duplicação e/ou replicação do DNA: a mitose. É na fase S de duplicação e/ou a replicação dos cromossomos, que a utilização de 5-bromodeoxiuridina (BrdU) é incorporada, identificando as células em proliferação, ou seja, durante a mitose, sendo a BrdU uma substância análoga da timidina., ${ }^{9,10}$

Vários autores descrevem trabalhos sobre a simplicidade das técnicas de BrdU como marcador e a conseqüente aplicação dessa técnica na área de genética para a identificação cromossômica.

Assim como a timidina, a BrdU é incorporada pelas células durante a fase $\mathrm{S}$ da mitose, marcando estas células em proliferação e sua progênie. Essa marcação pode ser visualizada através de técnicas imunocitoquímicas e o uso de radioisótopos, como a timidina. ${ }^{14}$

Muitos estudos demonstraram que as células-tronco relacionadas à cicatrização e regeneração tecidual são normalmente recrutadas para a região afetada por mecanismos específicos envolvendo moléculas de citocinas de matriz extracelular e proteínas de adesão.

A terapia celular emerge como opção terapêutica, visando retardar ou descartar a necessidade de transplante de órgão total e em vários tecidos, como no caso de falência cardíaca à semelhança do que foi já estabelecido em doenças hematológicas: anemias falciformes e leucemias. ${ }^{15}$
No entanto, para afirmar que essas terapias com célula-tronco são, de fato, procedimentos seguros e eficazes, há necessidade de se estabelecer critérios de segurança para seu potencial uso clínico. ${ }^{16}$ Para haver melhor prognóstico na terapia celular, é de fundamental importância que as células transplantadas estejam na fase proliferativa, condição básica para sua integração no tecido transplantado, assim como suas condições de integridade celular, com avaliações de índices de apoptose, viabilidade, estadiamento genético para identificar: alterações morfológicas, atipias celulares, instabilidade e anormalidades cromossômicas e elevada atividade de telomerases. ${ }^{17}$

O objetivo deste trabalho é estabelecer o protocolo do tempo de incubação para marcação celular com a BrdU de CTMO - fração mononuclear - através de estudo cinético para sua utilização na bioengenharia tecidual.

\section{MÉTODOS}

Todos os procedimentos experimentais para este estudo seguiram as normas do Colégio Brasileiro de Experimentação Animal. Foram utilizados dezesseis ratos machos da linhagem Wistar com peso médio de $300 \mathrm{~g}$, tendo sido distribuídos em quatro grupos de modo equânime entre os períodos pré-estabelecidos de incubação.

Obtenção de CTMO - fração mononuclear: Para obtenção do sangue da MO dos ratos foi utilizado o método de punção-aspiração precedido de anestesia: Ketamina $50 \mathrm{mg} / \mathrm{Kg}$ e Xilazina $10 \mathrm{mg} / \mathrm{Kg}$. Os animais foram colocados em posição de decúbito lateral com a perna superior flexionada e a inferior reta. A punção-aspiração foi realizada na crista ilíaca posterior do fêmur com seringa de $5 \mathrm{~mL}$ heparinizada com agulha $25 \times 7 \mathrm{~mm}$; foi coletado cerca de $01 \mathrm{~mL}$ de sangue da MO de cada rato e as seringas foram identificadas.

Isolamento de CTMO - fração mononuclear: O sangue obtido após a punção-aspiração da MO foi levado sob fluxo laminar em cabine de segurança biológica de classe II. Todas as soluções utilizadas no processo foram rigorosamente controladas quanto à esterilidade e composição.

No isolamento de CTMO - fração mononuclear - utilizou-se o gradiente de densidade ( $\mathrm{d}=1,077$, Ficoll-Hypaque-SIGMA) e o Meio de Dulbecco modificado por Iscove (IMDM-GIBCO-BRL) suplementado com $1 \%$ de antibiótico (penicilina e estreptomicina) e $20 \%$ de solução tampão. O material coletado foi adicionado em $9 \mathrm{~mL}$ de meio IMDM e foi acrescentado $3 \mathrm{~mL}$ de Ficoll-Hypaque e então centrifugado por 40 minutos a $400 \mathrm{~g}$ em temperatura de $18^{\circ} \mathrm{C}$. Após a centrifugação, foram aspirados $5 \mathrm{~mL}$ da camada de plasma junto ao meio e descartados, seguido de remoção cuidadosa do anel de CTMO - fração mononuclear - tendo sido transferido para outro tubo de $15 \mathrm{~mL}$, completando-o com o meio, seguido de centrifugação a $400 \mathrm{~g}$ por 10 minutos. O sobrenadante foi então desprezado e o precipitado foi re-suspenso no meio IMDM e novamente centrifugado a $400 \mathrm{~g}$ por 10 minutos, tendo sido retirado e desprezado o sobrenadante. ${ }^{18}$ A seguir, a contagem direta de células foi realizada no hemocitômetro com auxílio do azul de Trypan. As amostras de células foram submetidas à imunofenotipagem com auxílio de citometria de fluxo para os marcadores CD45 e CD34 e caracterização destas como CD45+ e CD34- (Clone OX-1 e Clone 581, Becton-Dickson).

Marcação de Células em Suspensão com a BrdU: As células foram re-suspensas no meio IMDM e acrescentada diretamente à 


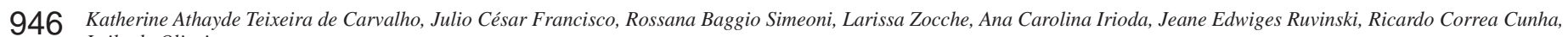
Leila de Oliveira

BrdU (SIGMA) na concentração final de $10 \mathrm{mM}$. As células foram incubadas nos períodos pré-estabelecidos: $1 \mathrm{~h}, 5 \mathrm{~h}, 16 \mathrm{~h}$ e $24 \mathrm{~h}$ e para cada amostra obtida em estufa de $\mathrm{CO}_{2}$ a $37^{\circ} \mathrm{C}$. Após o término de cada incubação, foi centrifugado por 10 minutos em temperatura ambiente à $300 \mathrm{~g}$ e o precipitado foi re-suspendido.

Imunofluorescência Direta: Retirada amostra de $12 \mu \mathrm{L}$ de um centrifugado de citospin de cada concentrado celular em uma lâmina. Logo após, esla foi colocada no freezer com metanol por 30 minutos. Incubou-se em $0,07 \mathrm{~N}$ de hidróxido de sódio $(\mathrm{NaOH})$ por dois minutos, sendo então lavado com tampão fosfato por cinco minutos; após, o pH foi alcalinizado para 8,5 visando neutralizar a base. Seguiu-se de lavagem em tampão fosfato por três vezes sob agitação durante cinco minutos. Diluiu-se o Anti-BrdU-FITC (SIGMA) e a amostra foi incubada por 30 minutos em câmara úmida em temperatura ambiente. Após 30 minutos, foram lavados em água destilada e as lâminas montadas com fluormonte seguidas de vedação e observação em microscópio de fluorescência. Cada amostra foi avaliada em 10 campos aleatórios por dois examinadores e com as mesmas objetivas 20x e 40x; sendo o resultado a média dessas observações.

Controle positivo: Para o controle positivo, o mesmo procedimento foi realizado do em células do produto de co-cultivo de mioblastos esqueléticos e CTMMO mantidas por 14 dias em meio para proliferação. ${ }^{19}$ As lâminas foram analisadas em microscópio de imunofluorescência (Olympus-Modelo IX-70).

\section{RESULTADOS}

Nas suspensões de CTMO - fração mononuclear (Figura 01) incubadas em suspensão por $1 \mathrm{~h}$ e $5 \mathrm{~h}$ foram observadas raras marcações com BrdU (Figura 02), enquanto nas suspensões incubadas por $16 \mathrm{~h}$ e $24 \mathrm{~h}$ (Figura 03) obteve-se marcações fortemente positivas e em maior número para $\operatorname{BrdU}(55 \% \pm 4 \%$, $16 \mathrm{~h}$ e $53 \pm 6 \%$, $24 \mathrm{~h}$ versus $12 \% \pm 3,1 \mathrm{~h}$ e $23 \pm 4,5 \mathrm{~h}$ ). Nas células do controle, produto do co-cultivo também houve forte marcação das células com $\operatorname{BrdU}(\geq 62 \%)$.

\section{DISCUSSÃO}

Neste estudo, demonstrou-se que a técnica com BrdU é capaz de identificar células de CTMO - fração mononuclear; uma vez que estas células foram marcadas, sugerindo que essas células estariam em atividade proliferativa, pois foi possível marcar células provenientes de co-cultivo sabidamente em proliferação.

Como a BrdU é uma substância marcadora da fase $\mathrm{S}$ do ciclo celular, ela marca qualquer tipo de célula, bastando estar na fase de proliferação. A marcação com BrdU pode ser usada para a análise prognóstica do potencial de integração dessas células no tecido transplantado, sendo que essa fração já é utilizada como tratamento estabelecido em doenças hematológicas e em modelos de miocardiopatias ao nível de pesquisa clínica em seres humanos.

Neste estudo, na incubação de BrdU em período de 1h, escassas marcações positivas foram observadas; isso nos sugere uma baixa eficiência na marcação durante esse período, e não o recomendamos; porém, alguns pesquisadores relatam que células em cultivo por $17 \mathrm{~h}$ e depois de incubadas com BrdU por $1 \mathrm{~h}$ a $2 \mathrm{~h}$, demonstraram condensação do cromossomo, assim como por um período de $5 \mathrm{~h} .{ }^{13}$ Nossa observação de um número maior de células se replicando com identificação de marcação mais forte foi a partir de $16 \mathrm{~h}$ de
Figura 1. Exemplo de Imunofenotipagem da Fração Mononucleada: CD45+ e CD34-.
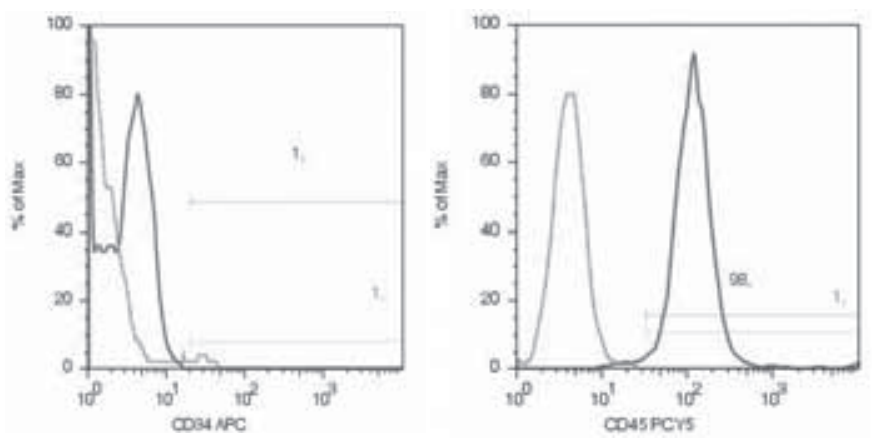

Figura 2. 1h de Incubação com BrdU. 400 x microscopia de fluorescência com marcação da BrdU.

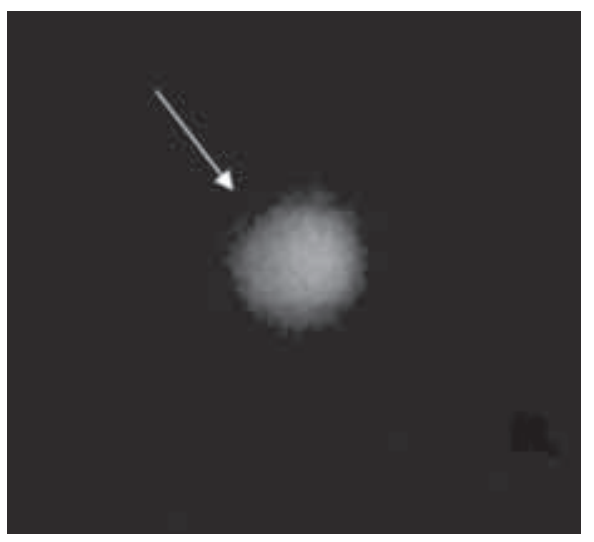

Figura 3. 24 h de Incubação de BrdU. 200x microscopia de fluorescência.

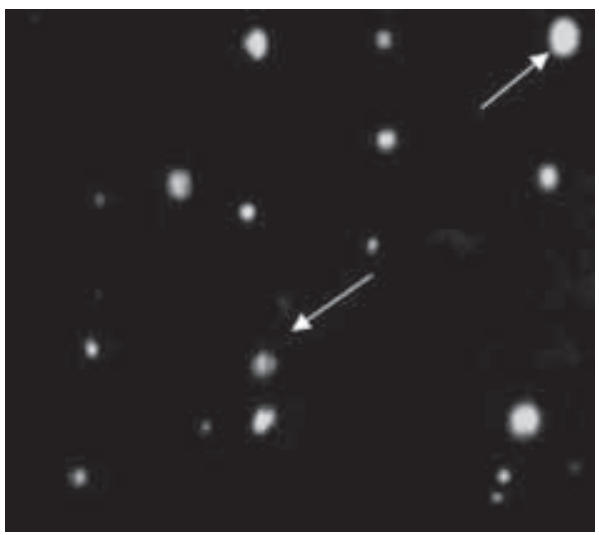

incubação com BrdU e enfatizando: em células não cultivadas. Outros autores demonstraram uma marcação efetiva quando as células são retiradas do cultivo celular em meio de proliferação ou integradas no tecido transplantado, sendo descrita marcação positiva com incubação de cardiomiócitos provenientes de cultivo com BrdU por $48 \mathrm{hs}$ in situ após quatro semanas de transplante no miocárdio receptor. ${ }^{20}$ 


\section{CONCLUSÕES}

Os períodos de incubação da BrdU para as CTMO - fração mononuclear - a partir de 16hs demonstraram ser a melhor opção para evidenciar a atividade proliferativa, sugerindo que seu uso seja incluído na rotina de terapia celular na avaliação prognóstica do potencial de integração no tecido transplantado e substituindo a timidina radioativa.

\section{ABSTRACT}

The 5-bromodeoyuridine is an analogous marker for the timidine, allowing to perform techniques such as immunocitochemstry, and widely used also to identify cells that proliferate in phase $\mathrm{S}$ of the cellular cycle. Purpose: The aim is to set the protocol to set the time of incubation to cell marker using the 5-bromodeoxyuridine of mononuclear bone marrow derived from stem cells through a kinetic study focusing the use in tissue bioengineering. Methods: 16 male Wistar rats with weight of $300 \mathrm{~g}$ were used. The bone marrow stem cells gathering was carried through the iliac crest punction-aspiration. The isolation was through the density gradient (Ficoll-Hypaque). Bone marrow stem cell (CD45+ and CD34-) suspensions were incubated with 5-bromodeoxyuridine in the final concentration of $10 \mathrm{mM}$ to $37^{\circ} \mathrm{C}$ in the settled periods of $1,5,16$, and $24 \mathrm{~h}$ for each sample, and followed by direct immunofluorescence. Results: All incubation periods of such cells had a positive marking for the 5-bromodeoxyuridine, meaning evidences in the proliferation phase of these cell suspensions, but from 16h on, we have demonstrated a better marker $(55 \% \pm 4 \%, 16 \mathrm{~h}$ and $53 \pm 6 \%, 24 \mathrm{~h}$ versus $12 \% \pm 3,1 \mathrm{~h}$ and $23 \pm 4$, 5h). Conclusions: The best incubation time for mononucleated cells was that of 16hs seeking to use such marker for those cells, and this protocol could be adopted in the routine analysis of the cell sampling for the cell therapy, being able to perform a prognostic for the cell integration potential predictor in the host tissue as well substituting the radioactive thimidine.

Key words: Stem Cells, Bone Marrow, Tissue Therapy,

\section{REFERÊNCIAS}

1. Smits AM, van Vliet P, Hassink RJ, Goumans MJ, Doevendans PA. The role of stem cells in cardiac regeneration. J Cell Mol Med. 2005;9(1):25-36.

2. Bianco P, Riminucci M, Gronthos S, Robey PG. Bone marrow stromal stem cells: nature, biology, and potential applications. Stem Cells. 2001;9(3):180-92.

3. Kuehnle I, Goodell MA. The therapeutic potential of stem cells from adults. BMJ. 2002;325(7360):372-6.

4. Strauer BE, Kornowski R. Stem cell therapy in perspective. Circulation. 2003; 107(7):929-34.

5. Pittenger MF, Martin BJ. Mesenchymal stem cells and their potential as cardiac therapeutics. Circ Res. 2004;95:9-20.

6. Verfaillie CM, Pera MF, Landsdorp PM. Stem cell: hype and reality. Hematology Am Soc Hematol Educ Program. 2002;369-91.

7. Phinney DG, Baddo M, Dutreil M, Gaupp D, Lai WT, Isakova IA. Murine mesenchymal stem cells transplanted to the central nervous system of neonatal versus adult mice exhibit distinct engraftment kinetics and express receptors that guide neuronal cell migration. Stem Cells Dev. 2006;15(3):437-47.

8. Stavrova LA, Fomina TI, Plotnikov, M, Aliev, O, Sotnikova, N, Epstein, O, et al. Pharmacological regulation of functional activity of stem cells in restoration of the myocardium during the postinfarction period. Bull Exp Biol Méd. 2005;140(5):593-7.

9. Gonchoroff NJ, Greipp PR, Kyle, RA, Katzmann, JA. A monoclonal antibody reactive with 5-bromo-2-deoxyuridine that does not require DNA desnaturation. Cytometry.1985;6:506-12.

10. Albert B, Bray D, Johnson A, Lewis J, Raff M, Roberts K, Walter P. Fundamentos da Biologia Celular: uma introdução à Biologia Molecular da Célula. Porto Alegre: Artmed; 1999.
11. Palmer CG. 5- bromodeoxyuridine constriction in human chromosomes. Can J Genet Cytol. 1970;12(4):816-30.

12. Zakharov NA, Egolina AF. Differential spiralization along mammalian mitotic chromosomes. I. BUdR-revealed differentiation in Chinese hamster chromosomes. Chromosoma. 1972;38(4):341-65.

13. Dutrillaux B, Fosse AM. The mechanism of chromosome segmentation induced by BUDR (5-bromodeoxyuridine). Ann Genet. 1974;17(3):207-11.

14. Kit S, Beck C, Graham OL, Gross A. Effect of 5-bromodeoxyuridine on deoxyribonucleic acid-thymine synthesis and cell metabolism of lymphatic tissues and tumors. Cancer Res. 1958;18(5):598-602.

15. Chachques JC, Salanson-Lajos C, Lajos P, Shafy A, Alshamry A, Carpentier A. Cellular cardiomyoplasty for myocardial regeneration. Asian Cardiovasc Thorac Ann. 2005;13(3):287-96.

16. Rubio D, García-Castro J, Martín MC, Fuente R, Cigudosa JC, Lloyd AC, Bernad A. Spontaneous Human Adult Stem Cells Transformation. Cancer Res. 2005;65(8):3035-39.

17. Artandi SE. Telomeres, Telomerase, and Human Disease. NEJM. 2006; 355(12):1195-97.

18. Boyum A. Isolation of mononuclear cells and granulocytes from human blood. Isolation of monuclear cells by one centrifugation, and of granulocytes by combining centrifugation and sedimentation at 1g. Scand J Clin Lab Invest Suppl. 1968;97:77-89.

19. Carvalho KA, Guarita-Souza LC, Simeone RB, Francisco JC, Olandoski M, Gremski W. Proliferation of bone marrow mesenchymal stem cells, skeletal muscle cells and co-culture of both for cell myocardium therapy in wistar rats. Transplant Proc. 2006; 38(6):1955-6.

20. Zhang $\mathrm{P}$, Zhang $\mathrm{H}$, Wang $\mathrm{H}$, Wei $\mathrm{Y}, \mathrm{Hu}$ S. Artificial matrix helps neonatal cardiomyocytes restore injured myocardiuminrats. Artif Organs. 2006;30(2):86-9. 